\title{
Rancangan sump dan sediment pond bukit 13 PT. Antam Tbk UBP bauksit tayan kalimantan barat
}

\author{
Murad \\ Universitas Tanjungpura, Jl. Prof. Dr. H. Hadari Nawawi, Pontianak, Indonesia \\ murad@teknik.untan.ac.id, murad.83ys@gmail.com
}

\begin{abstract}
ABSTRAK
Lokasi Bukit 13 sebagai target operasional PT. Antam Tbk UBP Bauksit Tayan belum ada kajian secara mendalam mengenai sistem penyaliran tambang, untuk itu perlu kajian awal terkait rancangan sump dan sediment pond agar tidak berdampak buruk bagi pencapaian produksi yang telah ditetapkan perusahaan. Tujuan penelitian membuat rancangan awal sistem penyaliran tambang yang baik dan efisien. Rancangan Sump dan Sediment Pond merupakan gabungan antara metode mine drainage dan mine dewatering. Berdasarkan analisis curah hujan tahun 2014-2019, diperoleh curah hujan rencana sebesar 151,844 mm/hari dengan periode ulang hujan 5 tahun dan resiko hidrologi sebesar 67,23\%. Debit limpasan air permukaan yang masuk ke bukaan tambang pada kolam pengendapan (Area Catchment 1) sebesar 2336,328 $\mathrm{m}^{3} / \mathrm{jam}$ dan Sump (Area Catchment 2) 993,6 m³ jam. Jumlah pompa yang digunakan sebanyak 1 unit merk Volvo KSB LCC- H 200-610 yang terletak pada sump. Hasil analisa data berdasarkan debit air limpasan dan airtanah, kapasitas pompa, volume dan waktu pemompaan, kajian teknis dan ekonomis; rancangan dimensi sump dipilih alternatif II berbentuk trapesium dengan kemiringan $60^{\circ}$. Sediment Pond dipilih alternatif I berbentuk persegi panjang ber zig zag dengan 4 kompartemen, hal tersebut diharapkan agar padatan yang masuk melalui inlet akan tertahan pada penyekat tiap kompartemen sehingga air yang keluar melalui outlet merupakan air yang sudah bersih. Untuk menghindari masuknya air limpasan dari front penambangan kelingkungan warga dengan cara memotong arah aliran air. Air yang masuk pada sump akan dilakukan pemompaan setiap satu bulan sekali dan pengendalian lumpur pada sediment pond menggunakan Excavator Long Arm Zaxis L210 setiap 11-30 hari sekali.
\end{abstract}

Kata kunci: Curah hujan, daerah tangkapan hujan, excavator, sump, dan kolam pengendapan lumpur.

\begin{abstract}
Design of sump and sediment pond on bukit 13 PT. Antam Tbk Bauksit UBP Tayan needs to be done to achieve the production that has been determined by the company. The research purpose is to design a good and efficient mine drainage system. The method used is a combination of mine drainage and mine dewatering. Analysis of rainfall in 2014-2019 is $151.844 \mathrm{~mm} /$ day and hydrological risk is $67.23 \%$. The runoff discharge in catchment area 1 is 2336,328 m3/hour and catchment area 2 is $993.6 \mathrm{m3/hour}$. The number of pumps used is 1 unit of the Volvo KSB LCC-H 200-610 brand which is placed in the sump. The results of the analysis of the sump dimension design data selected alternative II in the form of a trapezoid with a slope of $60^{\circ}$. The dimensions of the sediment pond were chosen as an alternative I in the form of a zig-zag rectangle with 4 compartments so that the solids entering through the inlet were retained in each compartment, then the water that came out through the outlet was clean. To avoid the entry of runoff water from the mining front into the residents' environment by cutting the direction of the water flow. The water entering the sump will be pumped once a month and the mud in the sediment pond dredged using the Zaxis L210 Long Arm Excavator every 11-30 days.
\end{abstract}

Keywords: Rainfall, catchment area, excavator, sump, and sediment pond.

diunggah: Oktober 2021, direvisi: November 2021, diterima: Desember 2021, dipublikasi: Desember 2021 Copyright (c) $2021 \mathrm{Murad}$

This is an open access article under the CC-BY license 


\section{PENDAHULUAN}

Metode tambang terbuka terutama pada Open Cast Mine akan menyebabkan terbentuknya cekungan yang luas sehingga sangat potensial untuk menjadi daerah tampungan air, baik yang berasal dari air limpasan permukaan. Pada saat kondisi cuaca yang ekstrim berupa curah hujan yang tinggi maka air yang berasal dari air limpasan akan menggenangi lantai dasar pit dan berpotensi menjadi salah satu penyebab berlumpurnya front penambangan dan menyebabkan terhentinya proses produksi untuk sementara waktu.

Saat ini PT. ANTAM Tbk. UBPB Tayan, Kalimantan Barat target operasional selanjutnya pada Bukit 13. Melalui rencana yang disusun berdasarkan kegiatan kerja yang telah dibuat oleh PT. ANTAM Tbk. UBPB Tayan, target produksi yang direncanakan oleh perusahaan sebesar 11.228 WMT CBx/hari, 320.000 WMT CBx/bulan, dan 6.487.242 WMT $\mathrm{CBx} /$ tahun. Hasil pengamatan selama di lapangan target produksi masih belum tercapai, diperkirakan hanya $80 \%$ tercapai dari target yang direncanakan. Salah satu faktor yang mempengaruhi adalah sistem penyaliran tambang yang kurang baik.

Pada lokasi Bukit 13 belum ada kajian secara mendalam mengenai penyaliran tambang, untuk itu perlu kajian awal terkait rancangan sump dan sediment pond agar tidak berdampak buruk bagi pencapaian produksi yang telah ditetapkan perusahaan. Dengan tidak terkontrolnya debit air yang masuk dan keluar dari tambang dapat mengakibatkan berbagai masalah seperti tergenangnya front loading, jalan tambang yang rusak dan licin,masuknya air limpasan ke lingkungan warga, efisiensi kerja menurun serta nantinya dapat mengancam keselamatan dan kesehatan kerja.

Berdasarkan beberapa penelitian yang telah dilakukan peneliti sebelumnya (Arief Rahmat Khusairi, Arindry, Budi Handayani, Chakti, Lesmana, Lidayul, Pipin Rio Sianturi, Raflesia, Stella Putri Pratama, Syaifullah Aziz, Thamrin, dan Widayat) terkait dengan permasalahan yang akan diteliti, dalam merencanakan dimensi sump dan sediment pond perlu memperhitungkan besar curah hujan rencana, intensitas curah hujan, luas daerah tangkapan hujan, debit limpasan serta dimensi paritan pada area penelitian.

Dalam menunjang jalannya aktivitas penambangan yang baik dibutuhkan suatu sistem penyaliran tambang yang efektif dan efisien, ditandai dengan tidak adanya air di front penambangan sehingga perlu dilakukan pemulihan pada sistem penyaliran tersebut.

Daerah penelitian diapit dengan lingkungan warga, yaitu Rawa Beganjing dan Danau Segelam. Danau segelam merupakan tempat mata pencaharian masyarakat sekitar sehingga hal inilah yang harus diperhatikan dalam pembuatan penyaliran yang benar. Harapannya dari penyaliran tersebut airlimpasan tidak masuk ke lingkungan warga.

Tujuan penelitian membuat rancangan awal sistem penyaliran tambang di Bukit 13 PT. ANTAM Tbk. UPB Bauksit Tayan terkait jumlah debit limpasan air permukaan yang masuk ke bukaan tambang pada kolam pengendapan (Area Catchment 1), jumlah pompa yang dibutuhkan untuk mengeluarkan air dalam sump, ukuran dimensi sump untuk menampung air limpasan dan dimensi kolam pengendapan/sediment pond, cara menghindari masuknya air limpasan dari front penambangan ke lingkungan warga, serta lamanya waktu pemompaan untuk mengeluarkan air dalam sump dan kolam pengendapan.

\section{METODE}

\section{Jenis penelitian}

Penelitian yang dilakukan adalah penelitian terapan (applied research) dengan melakukan eksperimen yaitu menggabungkan (korelasional) teori dan data lapangan untuk pemecahan masalah. Data yang akan ditampilkan pada penelitian ini adalah datakuantitatif (berupa angka-angka dan analisis menggunakan statistik). 
Sugiono (2012) menjelaskan bahwa penelitian kuantitatif "Metode penelitian yang berlandaskan pada filsafat positivisme, digunakan untuk meneliti pada populasi atau sampel tertentu, pengumpulan data menggunakan instrumen penelitian, analisis data bersifat kuantitatif dengan tujuan untuk menguji hipotesis yang telah ditetapkan. Filsafat positivisme memandang realitas/gejala/fenomena itu dapat diklasifikasikan, relative tetap, konkrit, teramati, terukur, dan hubungan gejala bersifat sebab akibat".

\section{Objek penelitian}

Objek penelitian adalah banyaknya volume air yang masuk dari air hujan, sehingga Sump dan Sediment Pond dapat menampung dan tidak mengakibatkan air tersebut melimpas kelingkungan warga maupun front penambangan. Dengan mengetahui banyaknya debit air yang masuk ke dalam bukaan tambang, maka perlu dibuat perencanaan dalam menangani maupun mencegah air yang akan masuk.

\section{Metode penyaliran tambang}

Sistem penyaliran yang direncanakan adalah gabungan antara metode mine drainage dan mine dewatering yaitu upaya untuk mencegah supaya air tidak masuk ke dalam area penambangan dan mengeluarkan air yang masuk ke lingkungan warga sesuai baku mutu, karena sebagian besar sumber airnya adalah berasal dari air hujan.

Sump dan Sediment Pond diletakkan pada lantai dasar bukaan tambang agar air yang berasal dari jenjang yang memiliki elevasi lebih tinggi dapat mengalir ke dalam sump secara alami dengan memanfaatkan gaya gravitasi. Bedanya sediment pond ini diidentikkan dengan memusatnya aliran air yang besar menuju ke daerah tersebut dan biasanya sediment pond ini menjadi tempat persinggahan terakhir air yang membawa sedimen itu mengalir.

Umumnya sediment pond ini berfungsi selama penambangan berlangsung atau tidak berpindah tempat, berbeda dengan sump yang dibuat jika estimasi penggunaannya tidak berlangsung lama, sehingga sump tersebut sifatnya hanya sementara yang menjadi tempat persinggahan air tersebut.

Air yang berasal dari beberapa paritan dialirkan menuju ke sediment pond untuk mengendapkan partikel-partikel padatan yang terbawa bersama dengan air. Beberapa paritan lainnya akan menuju ke tiap sump yang ditambahkan dengan treatment tambahan menggunakan zat kimia, sehingga air tersebut sudah sesuai baku mutu yang kemudian dialirkan menuju outlet. Hal ini dilakukan untuk mencegah terjadinya kekeruhan dan pendangkalan pada sungai serta memenuhi nilai baku mutu air limbah kegiatan penambangan seperti yang tecantum pada KEPMEN LH No. 113 Tahun 2003.

\section{Data dan Sumber Data}

Teknik pengumpulan data dengan melakukan observasi dan pengambilan data secara langsung di lapangan. Urutan pengumpulan data sebagai berikut:

1. Studi Literatur

Mempelajari data-data perusahaan dan laporan penelitian terdahulu.

2. Pengamatan Langsung di Lapangan

Meliputi orientasi lapangan bersama karyawan perusahaan untuk langkah awal penelitian, untuk mengidentifikasi masalah dan penentuan lokasi pengambilan data.

3. Pengumpulan Data 
Data primer berupa:

a. Kesediaan pompa atau alat gali dan pipa serta kondisinya.

b. Kondisi lahan bukaan tambang.

Data sekunder sebagai berikut:

a. Data curah harian minimum 5 tahun (2014-2019).

b. Peta topografi Bukit 13 .

c. Peta kontur Bukit 13.

d. Spesifikasi dan performa alat gali Long Arm Zaxis L210

e. Uji Pengukuran TSS

Instrumentasi (peralatan) yang dibutuhkan sebagai berikut:

a. Komputer/laptop

b. Peta lokasi penelitian

c. Software Surpac Geovia 6.6.2

d. Penggaris

e. Kamera

\section{Teknik analisis data}

Teknik analisis data yang dilakukan dengan menggabungkan antara teori dan data-data lapangan, sehingga dari keduanya didapatkan pendekatan penyelesaian masalah. Setelah mendapatkan data-data yang diperlukan penulis menggunakan rumus-rumus melalui literatur yang ada untuk menganalisis data. Analisis data yang dilakukan antara lain:

1. Luas catchment area yang dibagi dalam beberapa catchment padaBukit 13, tergantung pada kondisi bukit tersebut berdasarkan realisasi $O B$ Stripping.

2. Curah hujan rencana dengan metode Gumbel.

3. Intensitas hujan dengan rumus Mononobe.

4. Debit limpasan permukaan pada tiap catchment area.

5. Bentuk cebakan penyaliran Bukit 13 berdasarkan tata letak sump tiap catchment area.

6. Menghitung besar dimensi sump dan sedimen pond.

7. Menganalisis lama pengendapan materia pada sediment pond.

8. Menganalisis berapa lama sump dan sediment pond dapat dipulihkan. 


\section{Diagram alir penelitian}

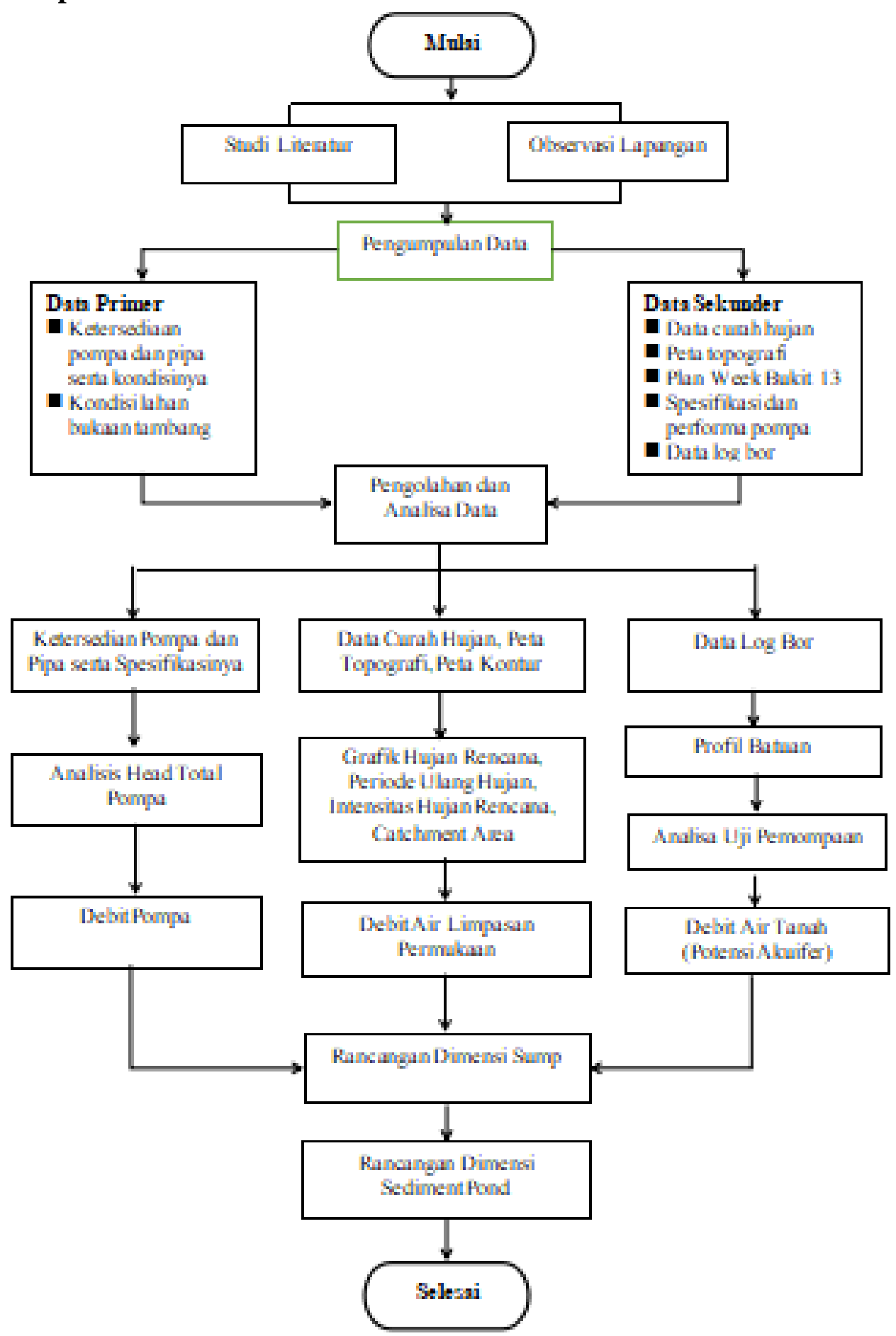

Gambar 1. Diagram alir penelitian

\section{HASIL DAN PEMBAHASAN}

\section{Catchment area/daerah tangkapan hujan}

Pembagian daerah tangkapan hujan dilakukan dengan pengamatan langsung di lapangan dan peta topografi Bukit 13. Pengamatan langsung di lapangan bertujuan untuk mengetahui arah aliran limpasan air dan koefisien limpasan yang cocok digunakan pada setiap catchment area, sehingga nantinya dapat di desain suatu sistem penyaliran yang dapat mengatasi permasalahan yang ada. Pengamatan pada peta topografi Bukit 13 untuk 
menentukan area yang lebih tinggi dan memiliki kemungkinan untuk menampung air hujan dan mengalirkannya ke lokasi tambang. Luas catchment area pada penelitian ini diperoleh dengan menggunakan software Surpac Geovia 6.62. Luas masing-masing catchment area Bukit 13 PT. Antam Tbk UBP Bauksit Tayan adalah sebagai berikut:

Tabel 1. Luas cathment area

\begin{tabular}{clrr}
\hline Catcment Area & \multicolumn{1}{c}{ Jenis } & Luas (ha) & Luas $\left(\mathrm{km}^{2}\right)$ \\
\hline I & Sediment Pond & 12,3515537 & 0,123515537 \\
II & Sump & 9,9467704 & 0,099467704 \\
\hline
\end{tabular}

\section{Koefisien limpasan}

Nilai koefisien limpasan diperoleh dari perbandingan antara jumlah air hujan yang jatuh di permukaan tanah dengan yang mengalir di permukaan tanah sebagai air limpasan dari hujan. Nilai koefisien limpasan (C) dipengaruhi oleh tata guna lahan dan kemiringan. Dari hasil pengamatan di lapangan dengan mengacu nilai koefisien limpasan menurut (Gautama, 2019) diperoleh nilai koefisien limpasan untuk masing-masing daerah tangkapan hujan adalah sebagai berikut.

Tabel 2. Koefisien limpasan pada cathment area

\begin{tabular}{ccc}
\hline Catcment Area & Nilai Koefisien Limpasan $(C)$ & Kemiringan dan Tata Guna Lahan \\
\hline I & 0,9 & $>15 \%$, Tanpa tumbuhan, daerah tambang \\
II & 0,9 & $>15 \%$, Tanpa tumbuhan, daerah tambang \\
\hline
\end{tabular}

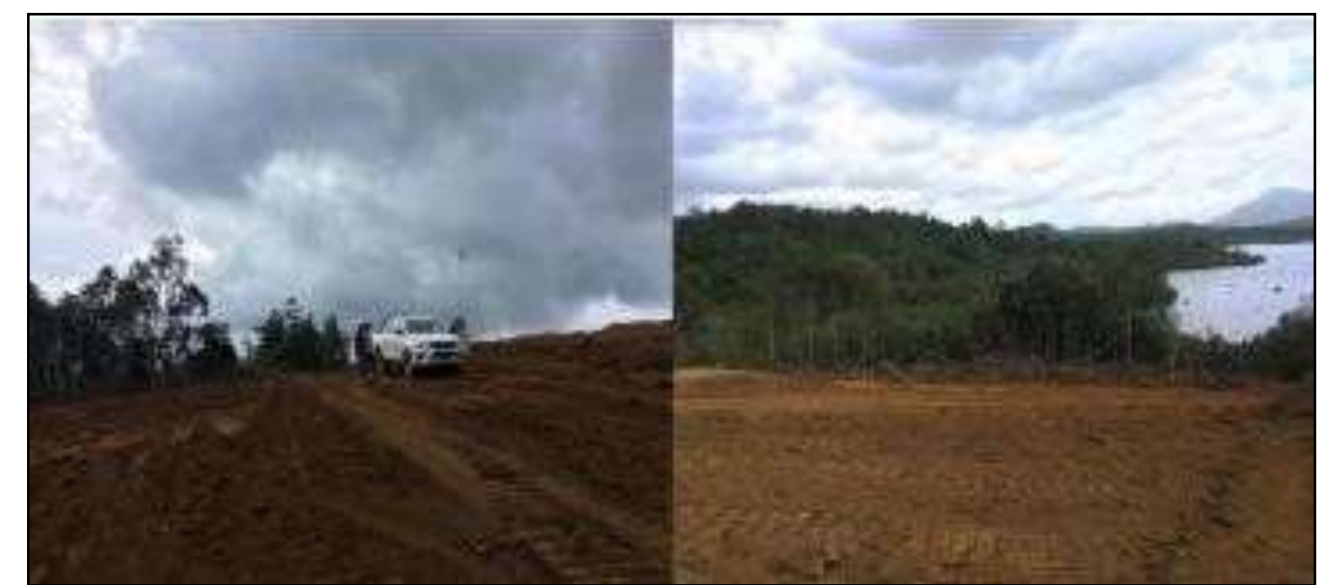

Gambar 2. Catchment area 1

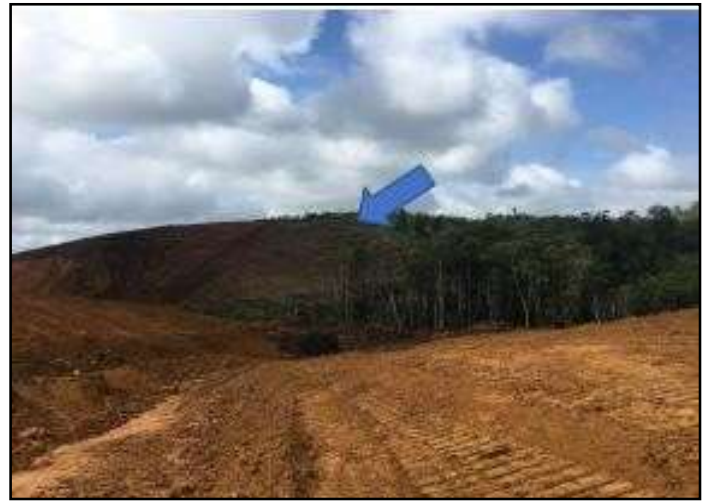

Gambar 3. Catchment area 2

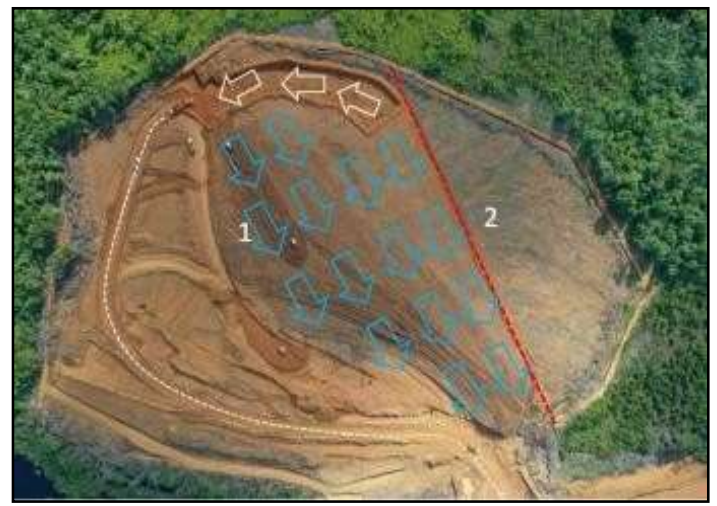

Gambar 4.Catchment area drone view

Sumber: Dokumen Mine Plan PT. Antam Tbk UBP Bauksit Tayan 2020 


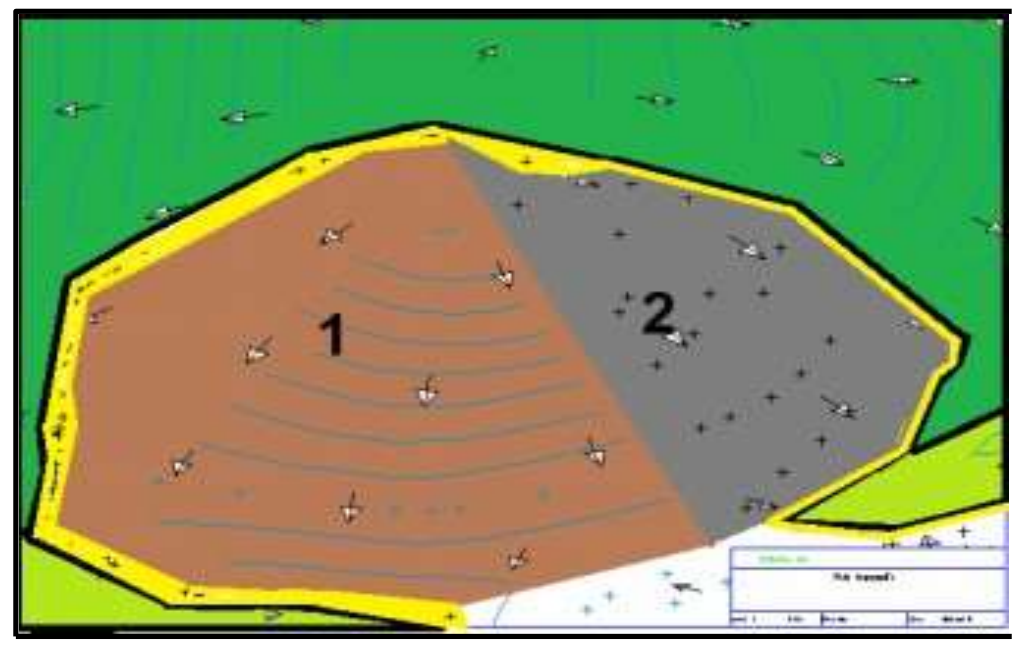

Gambar 5. Topografi berdasarkan tangkapan air hujan

\section{Curah hujan dan intensitas hujan rencana}

Curah hujan maksimum rata-rata sebesar $110,1667 \mathrm{~mm} /$ hari dan curah hujan rencana $151,844 \mathrm{~mm} /$ hari dengan periode ulang hujan 5 tahun dan resiko hidrologi sebesar $67,23 \%$. Data curah hujan diperoleh dari Department Health, Safety, \& Environment PT. Antam Tbk UBP Bauksit Tayan dengan lokasi stasiun pencatat curah hujan di PT. Indonesia Chemical Alumina.

Penentuan curah hujan rencana menggunakan analisis Annual Series. Data yang ada diolah dengan menggunakan Distribusi Gumbel.

Tabel 3. Curah hujan tayan hilir

\begin{tabular}{|c|c|c|c|c|c|c|c|c|c|c|c|c|c|}
\hline \multirow[t]{2}{*}{ Tahun } & \multicolumn{12}{|c|}{ Curah Hujan (mm) } & \multirow{2}{*}{$\begin{array}{c}\text { Curah Hujan } \\
\text { Maksimum (mm) }\end{array}$} \\
\hline & Jan & Feb & Mar & Apr & Mei & Jun & Jul & $\mathrm{Agt}$ & Sep & Okt & Nop & Des & \\
\hline 2014 & 39 & 96 & 125 & 68 & 155 & 102 & 72 & 37 & 23 & 45 & 90 & 28 & 155 \\
\hline 2015 & 82 & 62 & 53 & 33 & 73 & 48 & 0 & 0 & 0 & 0 & 0 & 0 & 82 \\
\hline 2016 & 62 & 110 & 81 & 33 & 75 & 31 & 59 & 28 & 81 & 46 & 112 & 39 & 112 \\
\hline 2017 & 48 & 119 & 54 & 115 & 57 & 51 & 73 & 84 & 95 & 78 & 127 & 85 & 127 \\
\hline 2018 & 117 & 90 & 80 & 70 & 80 & 120 & 27 & 40 & 70 & 60 & 89 & 40 & 120 \\
\hline 2019 & 66 & 55 & 21 & 54 & 0 & 0 & 0 & 0 & 0 & 0 & 0 & & 65 \\
\hline
\end{tabular}

Tabel 4. Curah hujan tayan hilir

\begin{tabular}{|c|c|c|c|c|c|c|c|c|c|c|}
\hline Tahun & $\begin{array}{c}\text { Curah Hujan } \\
\text { Maksimum } \\
\text { (X) }\end{array}$ & $\begin{array}{c}\text { Curah } \\
\text { Hujan Rata- } \\
\text { rata }(\bar{X})\end{array}$ & $(\mathrm{X}-\bar{X})^{2}$ & $\mathrm{n}$ & $\mathrm{M}$ & Yn & $\bar{Y} \mathrm{n}$ & $(\mathrm{Yn}-\bar{Y} \mathrm{n})$ & SD & Sn \\
\hline 2014 & 155 & \multirow{6}{*}{110,166} & 2010,02748 & \multirow{6}{*}{6} & 4 & $-0,01$ & \multirow{6}{*}{0,6491} & 0,5968 & \multirow{6}{*}{46,671} & \multirow{6}{*}{0,9528} \\
\hline 2015 & 82 & & 6724 & & 6 & 0,5 & & $-0,3148$ & & \\
\hline 2016 & 112 & & 3,36111 & & 1 & $-0,26$ & & 1,221 & & \\
\hline 2017 & 127 & & 16,833 & & 2 & 0,79 & & 0,44023 & & \\
\hline 2018 & 120 & & 96,695 & & 3 & 1,14 & & $-0,0685$ & & \\
\hline 2019 & 65 & & 2040,030789 & & 5 & $-0,53$ & & $-0,8745$ & & \\
\hline
\end{tabular}

Tabel 5. Curah hujan rencana pada periode ulang berbeda

\begin{tabular}{|c|c|c|c|c|c|c|c|c|c|}
\hline $\begin{array}{c}\text { Periode Ulang } \\
\text { Hujan (Tahun) }\end{array}$ & $\mathbf{2}$ & $\mathbf{3}$ & $\mathbf{4}$ & $\mathbf{5}$ & $\mathbf{6}$ & $\mathbf{7}$ & $\mathbf{8}$ & $\mathbf{9}$ & $\mathbf{1 0}$ \\
\hline Nilai Yt & 0,37 & 0,9 & 1,25 & 1,5 & 1,7 & 1,87 & 2,013 & 2,139 & 2,25 \\
\hline Nilai Yn & \multicolumn{7}{|c|}{0,6491} \\
\hline Nilai Sn & \multicolumn{8}{|c|}{0,9528} \\
\hline $\begin{array}{c}\text { Standard } \\
\text { Deviation (SD) }\end{array}$ & \multicolumn{10}{|c|}{} \\
\hline
\end{tabular}




\begin{tabular}{|c|c|c|c|c|c|c|c|c|c|}
\hline $\begin{array}{c}\text { Reduced Variate } \\
\text { Factor (k) }\end{array}$ & $-0,3$ & 0,263 & 0,63 & 0,893 & 1,103 & 1,281 & 1,432 & 1,5637 & 1,68 \\
\hline $\begin{array}{c}\text { Curah Hujan } \\
\text { Rata-rata }(\bar{X})\end{array}$ & \multicolumn{7}{|c|}{110,1667} \\
\hline $\begin{array}{c}\text { Curah Hujan } \\
\text { Rencana (Xt) }\end{array}$ & 95,16 & 122,46 & 139,57 & 151,844 & 161,65 & 169,95 & 177 & 183,15 & 188,57 \\
\hline
\end{tabular}

Intensitas hujan rencana dihitung berdasarkan nilai curah hujan rencana pada periode ulang 5 tahun dengan persamaan Mononobe. Berdasarkan perhitungan telah ditentukan besarnya curah hujan rencana pada periode ulang 5 tahun adalah sebesar 151,844 mm/hari dengan rata rata durasi hujan per tahunnya 2,5264 jam.

$$
\begin{aligned}
& \mathrm{I}=\frac{R_{24}}{24}\left(\frac{24}{t c}\right)^{2 / 3} \\
& \mathrm{I}=\frac{151,844 \mathrm{~mm}}{24}\left(\frac{24}{2,5264 \mathrm{jam}}\right)^{2 / 3}=\frac{151,844 \mathrm{~mm}}{24}(4,485)=28,38 \mathrm{~mm} / \mathrm{jam}
\end{aligned}
$$

\section{Debit air limpasan permukaan}

Debit air limpasan dapat ditentukan setelah diketahui luas masing masing catchment area/daerah tangkapan hujan, nilai intensitas curah hujan dan nilai koefisien limpasan. Untuk memperkirakan debit air limpasan dapat digunakan rumus rasional (Gautama, RS. 2019) sebagai berikut:

$$
Q=0,278 \times C \times I \times A
$$

$$
\begin{aligned}
& \text { Keterangan: } \\
& \mathrm{Q}=\text { Debit air, } \mathrm{m}^{3} / \text { detik } \\
& \mathrm{C}=\text { Koefisien limpasan } \\
& \mathrm{I}=\text { Intensitas curah hujan, } \mathrm{mm} / \mathrm{jam} \\
& \mathrm{A}=\text { Luas daerah tangkapan hujan, } \mathrm{Km}^{2}
\end{aligned}
$$

\begin{tabular}{|c|c|c|c|c|c|}
\hline $\begin{array}{c}\text { Catcment } \\
\text { Area }\end{array}$ & Luas $\left(\mathrm{km}^{2}\right)$ & $\begin{array}{c}\text { Koefisien } \\
\text { Limpasan }(C)\end{array}$ & $\begin{array}{l}\text { Intensitas Hujan } \\
(\mathrm{mm} / \mathrm{jam})\end{array}$ & $\begin{array}{l}\text { Debit (Q) } \\
\left(\mathrm{m}^{3} / \mathrm{det}\right)\end{array}$ & $\begin{array}{c}\text { Debit }(\mathrm{Q}) \\
\left(\mathrm{m}^{3} / \mathrm{jam}\right)\end{array}$ \\
\hline I & 0,12352 & 0,9 & \multirow{2}{*}{28,38} & 0,649 & 2336,328 \\
\hline II & 0,09947 & 0,9 & & 0,276 & 933,6 \\
\hline
\end{tabular}

Perhitungan debit air limpasan permukaan pada catchment area 1

$$
\begin{aligned}
\mathrm{Q} & =0,278 \times \mathrm{C} \times \mathrm{I} \times \mathrm{A} \\
& =0,278 \times 0,9 \times 28,38 \times 0,0913961 \mathrm{~km}^{2} \\
& =0,64898 \mathrm{~m}^{3} / \text { detik } \\
& =0,64898 \mathrm{~m}^{3} / \text { detik } \times 3600 \\
& =2336,328 \mathrm{~m}^{3} / \mathrm{jam}
\end{aligned}
$$

Tabel 6. Debit air limpasan permukaan bukit 13

\section{Pompa}

Perencanaan dimensi sump dalam penelitian ini melibatkan pompa Volvo KSB LCC-H 200-610. Pipa yang digunakan jenis pipa HDPE (High Density Poly Ethnyl) PN 16 PE 100 diameter 14 inci dan 12 inci untuk sisi inlet.

Air yang dipompa akan dialirkan menuju kolam pengendapan lumpur/sediment pond 23 dengan sistem pemompaan estafet. 


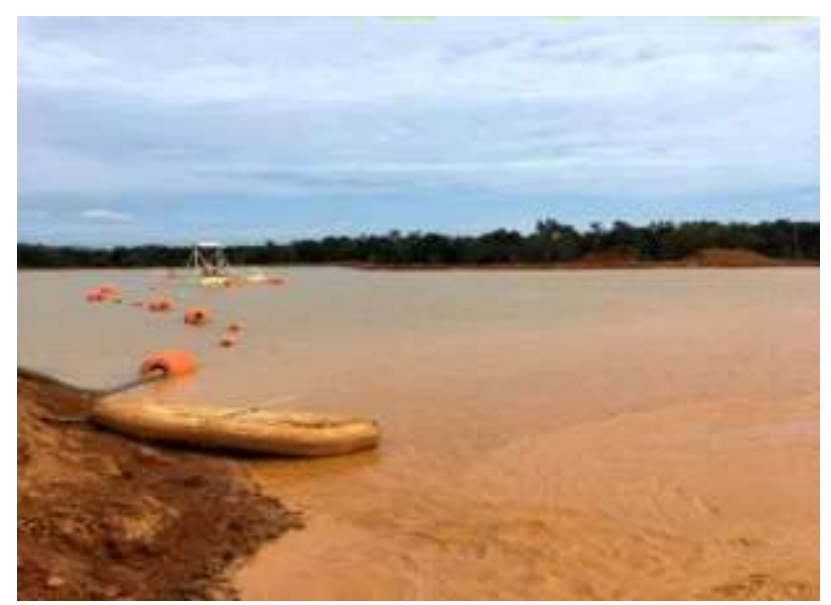

Gambar 6. Sistem Pemompaan Estafet

\section{Rancangan Sump}

Penentukan dimensi sump tambang sangat bergantung pada debit air limpasan baik permukaan maupun air tanah, kapasitas pompa, volume dan waktu pemompaan.

Tabel 7. Volume air total

\begin{tabular}{|c|c|c|c|c|c|}
\hline Jenis & $\begin{array}{c}\text { Debit Air } \\
\text { Permukaan } \\
\left(\mathrm{m}^{3} / \text { hari }\right)\end{array}$ & $\begin{array}{c}\text { Debit AirTanah } \\
\left(\mathrm{m}^{3} / \text { hari }\right)\end{array}$ & $\begin{array}{c}\text { Vol. Total } \\
\text { Inflow }\left(\mathrm{m}^{3} / \mathrm{hari}\right)\end{array}$ & $\begin{array}{c}\text { Volume } \\
\text { Pemompaan } \\
\left(\mathrm{m}^{3} / \text { hari }\right)\end{array}$ & $\begin{array}{c}\text { Vol. Air Total } \\
\left(\mathrm{m}^{3} / \mathrm{hari}\right)\end{array}$ \\
\hline Sediment Pond & 7008,984 & 1575 & 8583,984 & 0 & 8583,984 \\
\cline { 4 - 6 } Sump & 2980,8 & & 4555,8 & 1120 & 4555,8 \\
\hline
\end{tabular}

Tabel 8. Analisis dimensi sump

\begin{tabular}{|c|c|c|c|c|c|}
\hline $\begin{array}{c}\text { Alternatif } \\
\text { Sump }\end{array}$ & $\begin{array}{c}\text { Kedalaman } \\
(\mathrm{m})\end{array}$ & $\begin{array}{c}\text { Kemiringan } \\
\left({ }^{\circ}\right)\end{array}$ & $\begin{array}{c}\text { Panjang dan Lebar } \\
\text { Permukaan }(\mathrm{m})\end{array}$ & $\begin{array}{c}\text { Panjang dan Lebar } \\
\text { Dasar }(\mathrm{m})\end{array}$ & $\begin{array}{c}\text { Vol. Dapat } \\
\text { Ditampung }\left(\mathrm{m}^{3}\right)\end{array}$ \\
\hline I & 3 & 60 & 40 & 37,5 & 4509,375 \\
\hline II & 3 & 60 & 41 & 38 & 4687,50 \\
\hline III & 3 & 60 & 42 & 38,5 & 4869,375 \\
\hline
\end{tabular}

\section{Perencanaan Sediment Pond}

Pembuatan kolam pengendapan lumpur/sediment pond bertujuan untuk mengendapkan lumpur-lumpur atau material padatan yang bercampur dengan air limpasan yang disebabkan adanya aktivitas penambangan maupun karena erosi. Disamping itu, kolam pengendapan juga dapat berfungsi sebagai tempat pengontrol kualitas dari air yang akan dialirkan keluar kolam pengendapan, baik itu kandungan materialnya, tingkat keasaman ataupun kandungan material lain yang dapat membahayakan lingkungan.

Tabel 9. Dimensi sediment pond

\begin{tabular}{|c|c|c|c|c|}
\hline \multirow[t]{2}{*}{ No. } & \multirow{2}{*}{ Dimensi Sediment Pond } & \multicolumn{3}{|c|}{ Alternatif } \\
\hline & & $\mathrm{I}$ & II & III \\
\hline 1. & Lebar Kolam (m) & 40 & 45 & 45 \\
\hline 2. & Panjang Kolam (m) & 55 & 50 & 52 \\
\hline 3. & Lebar Penyekat (m) & 5 & 4 & 4 \\
\hline 4. & Panjang Penyekat (m) & 30 & 35 & 35 \\
\hline 5. & Banyak Kompartemen & 4 & 4 & 4 \\
\hline 6. & Lebar Masing-masing Kompartemen (m) & 10 & 9,5 & 10 \\
\hline 7. & Banyak Penyekat & 3 & 3 & 3 \\
\hline 8. & Kedalaman Kolam (m) & 5 & 5 & 5 \\
\hline 9. & Kapasitas Seluruh Kompartemen $\left(\mathrm{m}^{3}\right)$ & 8.750 & 9.150 & 9.600 \\
\hline 10. & Kapasitas Tiap Kompartemen $\left({ }^{3}\right)$ & 2.000 & $2.137,5$ & 2.250 \\
\hline
\end{tabular}


Sebelum menentukan ukuran kolam pengendapan, terlebih dahulu harus diketahui persen pengendapan yang terkandung di dalam air tambang yang akan dialirkan menuju kolam pengendapan. Dari hasil pengambilan sampel pada uji kualitas, diperoleh nilai TSS (Total Suspended Solid/Total Residu Tersuspensi) pada sebuah paritan adalah sebesar 583,33 $\mathrm{mg} / \mathrm{liter}$.
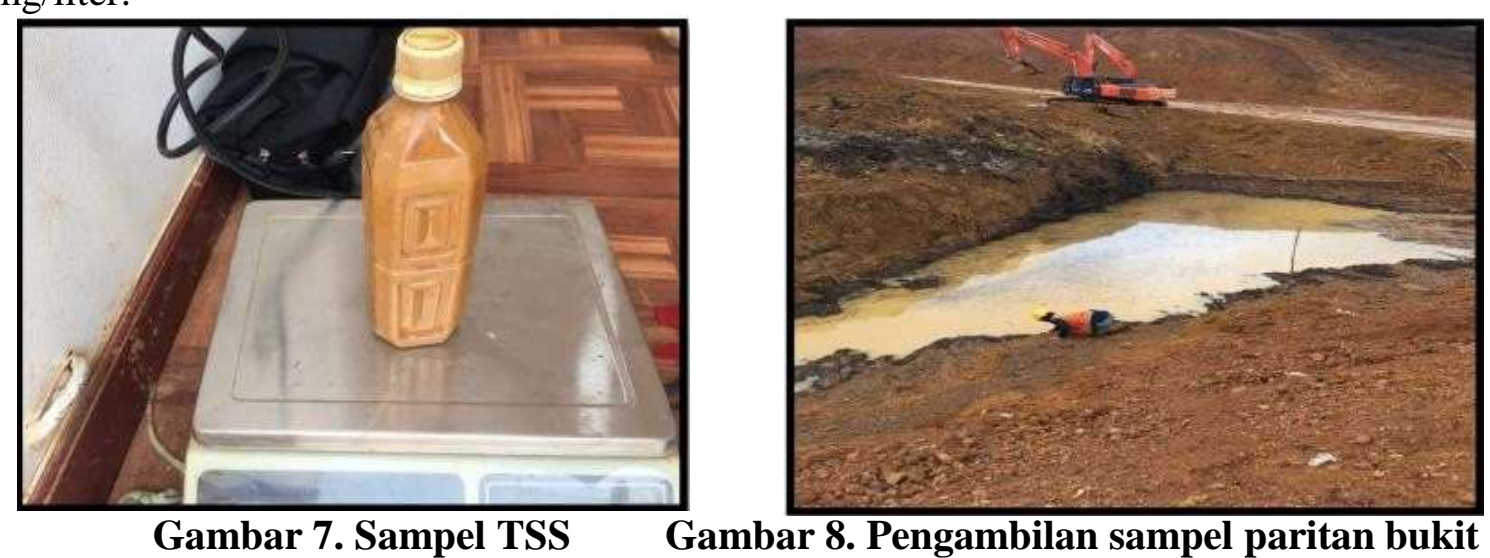

Gambar 7. Sampel TSS

Gambar 8. Pengambilan sampel paritan bukit 13

Diketahui debit yang masuk ke kolam pengendapan lumpur adalah 0,64898 $\mathrm{m}^{3} / \mathrm{detik}$. Residu tersuspensi $=583,33 \mathrm{gr} / \mathrm{m}^{3} \times 0,64898 \mathrm{~m}^{3} / \mathrm{detik}=378,5695 \mathrm{gr} / \mathrm{detik}$.

Tabel 10. Analisis residu tersuspensi

\begin{tabular}{|c|c|c|c|}
\hline Jenis & TSS $\left(\mathrm{gram} / \mathrm{m}^{3}\right)$ & Debit Air $(\mathrm{m} 3 / \mathrm{det})$ & $\begin{array}{c}\text { Residu Tersuspensi } \\
\text { (gr/detik) }\end{array}$ \\
\hline Sediment Pond & 583,33 & 0,64898 & 378,5695 \\
\hline Sump & 583,33 & 276 & 160,9991 \\
\hline
\end{tabular}

Berdasarkan persamaan $\rho=\frac{m}{v}$, diketahui $\rho$ partikel padatan adalah $1730 \mathrm{~kg} / \mathrm{m}^{3}$ (engineeringtoolbox.com) maka volume padatan yang masuk pada sediment pond,

Tabel 11. Analisis volume padatan masuk

\begin{tabular}{|l|c|c|}
\hline \multicolumn{1}{|c|}{ Jenis } & Residu Tersuspensi (gr/detik) & Volume Padatan Masuk $\left(\mathrm{m}^{3} / \mathrm{detik}\right)$ \\
\hline Sediment Pond & 378,5695 & 0,00021883 \\
\hline Sump & 160,9991 & 0,0000930631 \\
\hline
\end{tabular}

Dari hasil sampel TSS bahwa perbandingan persen air dengan padatan adalah 60:40, maka untuk persen padatan yang kurang dari $40 \%$ digunakan persamaan "stokes".

Ukuran dimensi kolam pengendapan yang dibuat harus mempertimbangkan luas lahan yang tersedia dan spesifikasi alat gali yang akan beroperasi dalam perawatan kolam. Alat yang digunakan oleh PT. Antam Tbk UBP Bauksit Tayan adalah Excavator Long Arm Zaxis L210. Waktu yang dibutuhkan partikel untuk mengendap (tv) adalah tv $=\frac{h}{V t}$

Tabel 12. Waktu partikel mengendap

\begin{tabular}{|c|c|c|c|}
\hline Jenis & $\begin{array}{c}\text { Kedalaman (h) } \\
(\text { meter})\end{array}$ & $\begin{array}{c}\text { Kecepatan Pengendapan Partikel (Vt) } \\
(\mathrm{m} / \mathrm{s})\end{array}$ & $\begin{array}{c}\text { Waktu Partikel Mengendap (tv) } \\
\text { (menit) }\end{array}$ \\
\hline Sediment Pond & 5 & 0,001938 & 43 \\
\hline Sump & 3 & 0,001938 & 26 \\
\hline
\end{tabular}

Waktu yang dibutuhkan material untuk keluar dari kolam pengendapan (th). Partikel-partikel padatan dapat mengendap dengan baik jika $t v<$ th. Kecepatan air dalam kolam adalah $\mathrm{Vh}=$ $\frac{Q}{A}$ 
$\mathrm{Vh}=\frac{\mathrm{Q}}{\frac{\mathrm{L1+L2}}{2} \times \mathrm{h}}=\frac{0,64898 \mathrm{~m}^{3} / \mathrm{det}}{\frac{62 \mathrm{~m}+52 \mathrm{~m}}{2} \times 5 \mathrm{~m}}=0,002822 \mathrm{~m} / \mathrm{det}$

Waktu yang dibutuhkan air dan material tersuspensi keluar dari kolam pengendapan dapat dicari dengan rumus $\mathrm{Th}=\mathrm{P} / \mathrm{Vh}$ (detik)

$$
\begin{gathered}
\mathrm{Th}_{1}=\frac{\mathrm{P} 1}{\mathrm{Vh}}=\frac{42 \mathrm{~m}}{0,002822 \mathrm{~m} / \mathrm{det}}=14883,0.6165 \text { detik }=4,1342 \mathrm{jam} \\
\mathrm{Th}_{2}=\frac{\mathrm{P} 2}{\mathrm{Vh}}=\frac{98 \mathrm{~m}}{0,002822 \mathrm{~m} / \mathrm{det}}=34727,144 \mathrm{detik}=9,6464 \mathrm{jam} \\
\mathrm{Th}_{3}=\frac{\mathrm{P} 3}{\mathrm{Vh}}=\frac{154 \mathrm{~m}}{0,002822 \mathrm{~m} / \mathrm{det}}=545471,081 \text { detik }=15,15867 \mathrm{jam} \\
\mathrm{Th}_{4}=\frac{\mathrm{P} 4}{\mathrm{Vh}}=\frac{210 \mathrm{~m}}{0,002822 \mathrm{~m} / \mathrm{det}}=74415,3083 \text { detik }=20,6 \mathrm{jam}
\end{gathered}
$$

Berdasarkan perhitungan didapatkan nilai tv $<$ th. Dengan membandingkan waktu pengendapan dan waktu keluarnya air dan material dapat digunakan rumus, $\%$ pengendapan $=\frac{T h}{T h+T v}=100$

Setelah \% Pengendapan pada masing- masing kompartemen diketahui, kemudian dapat dihitung padatan yang masuk padasetiap kompartemen dengan debit $0,99865 \mathrm{~m}^{3} / \mathrm{detik}_{\text {dan }}$ volume padatan masuk (vpm) sebesar $0,00033673 \mathrm{~m}^{3} /$ detik adalah:

$$
\begin{aligned}
& \mathrm{K} 1=0,00021883 \mathrm{~m}^{3} / \text { detik } \times 3.600 \times 3 \mathrm{jam} \times 85,22=201,40588 \mathrm{~m}^{3} / \mathrm{hari} \\
& \mathrm{K} 2=0,00021883 \mathrm{~m}^{3} / \text { detik } \times 3.600 \times 3 \mathrm{jam} \times 13,754=32,506 \mathrm{~m}^{3} / \mathrm{hari} \\
& \mathrm{K} 3=0,00021883 \mathrm{~m}^{3} / \text { detik } \times 3.600 \times 3 \mathrm{jam} \times 0,975=2,30428 \mathrm{~m}^{3} / \mathrm{hari} \\
& \mathrm{K} 4=0,00021883 \mathrm{~m}^{3} / \text { detik } \times 3.600 \times 3 \mathrm{jam} \times 0,0445=0,10517 \mathrm{~m}^{3} / \mathrm{hari}
\end{aligned}
$$

Tabel 13. Padatan yang berhasil masuk

\begin{tabular}{|l|c|}
\hline \multicolumn{1}{|c|}{ Jenis } & Padatan $\left(\mathrm{m}^{3} / \mathrm{hari}\right)$ \\
\hline Sediment Pond & 236,32133 \\
\hline Sump & 100,51 \\
\hline
\end{tabular}

Untuk menjaga agar supaya kolam pengendapan tetap berfungsi sebagaimana mestinya, maka perlu dilakukan perawatan secara teratur yaitu dengan melakukan pengerukan terhadap kolam pengendapan. Pengerukan kolam akan dilakukan jika lumpur sudah terendapkan 1/4 dari kapasitas kolam. Persentase padatan yang masuk akan berbeda setiap kompartemennya, maka waktu pengerukan masing-masing kompartemen akan berbeda pula.

Waktu Pengerukan $=\frac{\text { Kapasitas Kompartemen }}{\text { Vol.Total Padatan yg Diendapkan }}=\frac{2100 \mathrm{~m}^{3}}{236,32133 \mathrm{~m}^{3} / \text { hari }}=11$ hari Tabel 14. Padatan yang berhasil masuk

\begin{tabular}{|l|c|c|c|}
\hline \multicolumn{1}{|c|}{ Jenis } & Kapasitas $\left(\mathrm{m}^{3}\right)$ & Volume Padatan $\left(\mathrm{m}^{3} /\right.$ hari $)$ & Waktu Pemulihan \\
\hline Sediment Pond & 2100 & 201,40588 & $11-30$ hari \\
\hline Sump & 4687,5 & 178,956 & $30-46$ hari \\
\hline
\end{tabular}




\section{Sistem Penyaliran Bukit 13}

Rancangan sistem penyaliran Bukit 13 merupakan penggabungan antara metode mine dewatering dan mine drainage. Ketika air masuk pada elevasi titik tertinggi pada Bukit 13 terdapat 2 arah tangkapan air hujan yang bertolak arah sehingga diperlukan tempat penampungan pada tiap catchment.

Berdasarkan pertimbangan teknis dan ekonomis untuk dimensi sump dipilih alternatif II (panjang dan lebar permukaan $41 \mathrm{~m}$, panjang dan lebar dasar $38 \mathrm{~m}$, kedalaman $3 \mathrm{~m}$, dan kemiringan $60^{\circ}$ ) dengan volume air limpasan yang dapat ditampung sebesar $4687,50 \mathrm{~m}^{3}$.

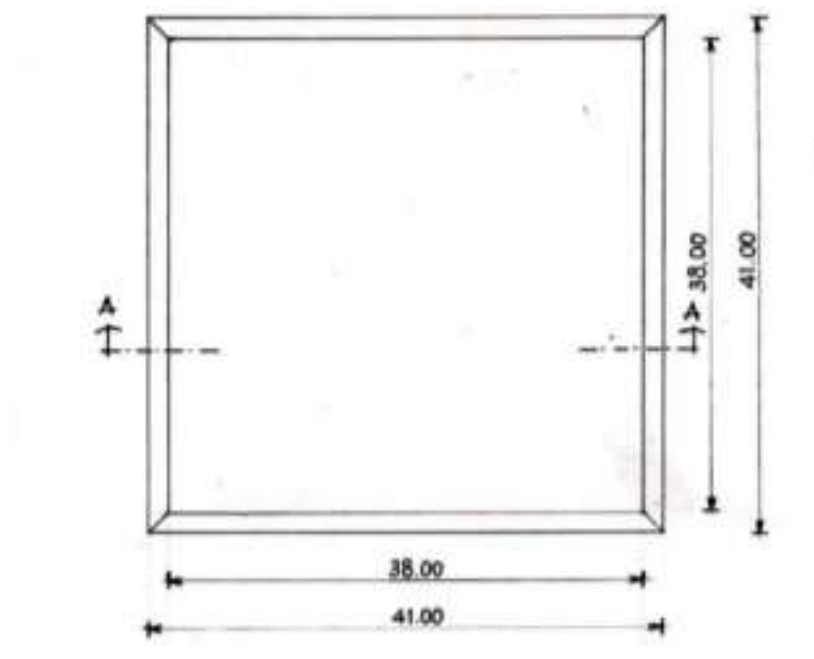

Gambar 9. Lay out sump

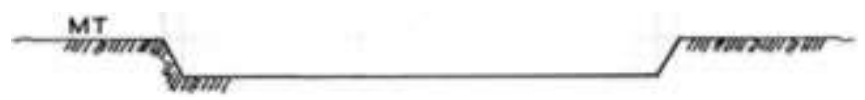

Gambar 10. Potongan A-A

Dimensi sediment pond dipilih alternatif I dengan ukuran (lebar kolam $40 \mathrm{~m}$, panjang kolam $55 \mathrm{~m}$, panjang penyekat $5 \mathrm{~m}$, banyak kompartemen 4 buah, lebar masing-masing kompartemen $10 \mathrm{~m}$, banyak penyekat 3 buah, kedalam kolam $5 \mathrm{~m}$ ) dengan kapasistas tiap kompartement $2.000 \mathrm{~m}^{3}$ dan kapasitas seluruh kompartemen $8.750 \mathrm{~m}^{3}$.

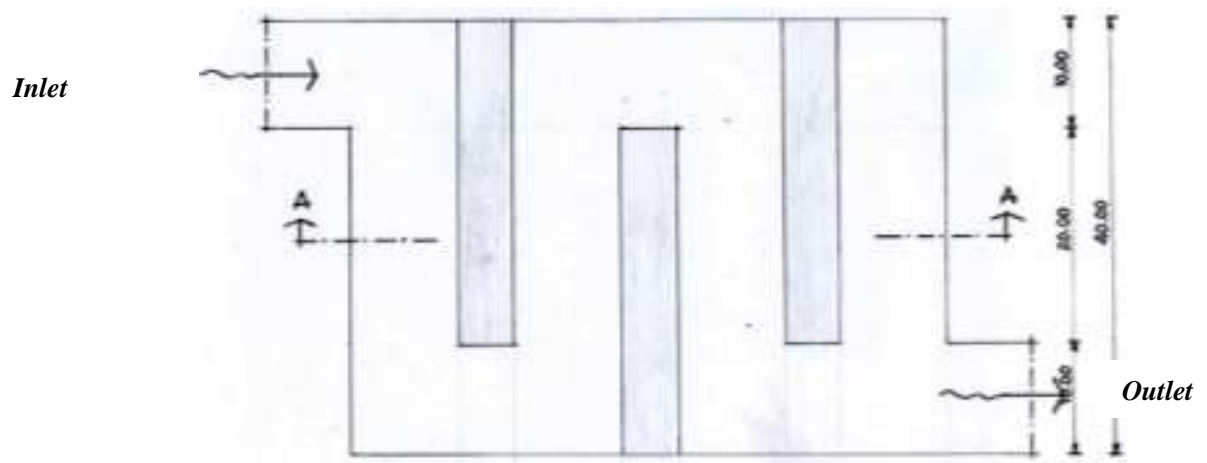

Gambar 11. Lay out sediment pond

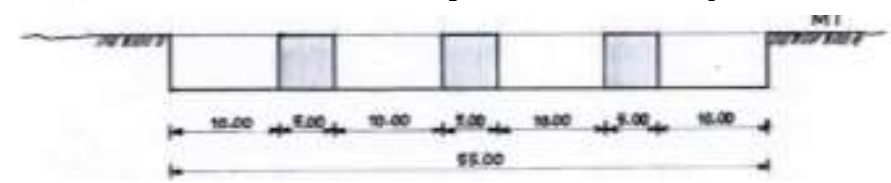

Gambar 12. Potongan A-A 
Pada catchment 1 air akan masuk menuju kolam pengendapan, ketika air masuk bersama dengan material sedimen akan ada proses tertahannya sedimen disetiap sekat dikarenakan kolam tersebut berbentuk zig-zag, sehingga air yang dikeluarkan melalui outlet air tersebut sudah dalam kondisi bersih dan sudah melalui nilai baku mutu. Lumpur yang terendapkan akan dikeruk menggunakan Excavator Long Arm Zaxis L210. Pada catchment 2 air akan masuk menuju sump yang akan dilakukan pemulihan dengan menggunakan pompa volvo, sehingga air dan lumpur tersebut akan dialirkan menuju kolam 23 dan selajutnya dilakukan watertreatment pond sehingga air tersebut dapat digunakan kembali pada pencucian material.

\section{SIMPULAN}

Debit limpasan air permukaan yang masuk ke bukaan tambang pada kolam pengendapan (Area Catchment 1) sebesar 2336,328 $\mathrm{m}^{3} / \mathrm{jam}$ dan Sump (Area Catchment 2) $993,6 \mathrm{~m}^{3} / \mathrm{jam}$. Jumlah pompa yang digunakan sebanyak 1 unit merk Volvo KSB LCC- H 200-610 yang terletak pada sump. Dimensi sump direkomendasikan alternatif II dan sediment pond alternatif I dari tiga alternatif yang dirancang. Dengan padatan material yang berhasil masuk setiap kali hujan perharinya pada sump $100,51 \mathrm{~m}^{3}$, dan pada kolam pengendapan sebesar $236,32133 \mathrm{~m}^{3}$.

Untuk menghindari masuknya air limpasan dari front penambangan ke lingkungan warga (Danau Segelam dan Rawa Beganjing) dengan cara memotong arah aliran air dan meletakkan tempat penampungan pada setiap catchment, sehingga air kotor yang berasal dari Bukit 13 dapat tertampung di elevasi terendah, dan tidak mengalir ke lingkungan warga. Air yang masuk pada sump akan dilakukan pemompaan setiap satu bulan sekali, pengerukan lumpur pada sediment pond menggunakan Excavator Long Arm Zaxis L210 dilakukan setiap 11-30 hari sekali.

Perlu dilakukan kajian lanjutan secara mendalam terkait sistem penyaliran tambang yang baik dan efisien dari segi teknis dan ekonomis dengan waktu penelitian yang terprogram dan data-data curah hujan yang lengkap dan siklus yang panjang.

\section{DAFTAR PUSTAKA}

Alviansyah, Novialdy. 2019. "Perencanaan Desain Kolam Pengendapan Pada Bukit 7 PT. ANTAM Tbk UBP Bauksit, Tayan, Kabupaten Sanggau, Provinsi Kalimantan Barat”. Skripsi. Jakarta: Universitas Islam Negeri Syarif Hidayatullah.

Anonim. 2020. Dokumen PT. ANTAM Tbk.UBPB Tayan, Kalimantan Barat. Pontianak: PT. ANTAM Tbk. UBPB Tayan, Kalimantan Barat.

Anonim. 2020. Mine Operation Mining Department PT. ANTAM Tbk. UBPB Tayan, Kalimantan Barat. Pontianak: PT. ANTAM Tbk. UBPB Tayan, Kalimantan Barat.

Anonim. 2020. Health, Safety, and Environment Department PT. ANTAM Tbk. UBPB Tayan, Kalimantan Barat. Pontianak: PT. ANTAM Tbk. UBPB Tayan, Kalimantan Barat.

Arief Rahmat Khusairi, Tamrin Kasim, dan Yunaril. "Kajian Teknis Sistem Penyaliran Tambang pada Tambang Terbuka Batubara PT. Nusa Alam Lestari, Kenagarian Sinamar, Kecamatan Asam Jujuhan, Kabupaten Dharmasraya.”Jurnal Bina Tambang, Vol. 3, No. 3 (ISSN: 2302-3333). Hlm. 1202-1212. 
Arindry, A. P. P., \& Herlambang, Y. Evaluasi Kapasitas Kolam Pengendapan Unit Pencucian Bauksit Pada Washing Plant Cabing KM 23 PT. Dinamika Sejahtera Mandiri Site Teraju. Jurnal Mahasiswa Teknik Sipil Universitas Tanjungpura, 7(1).

Bedient, P. B., Rifai, H. S., \& Newell, C. J. 1994. Ground water contamination: transport and remediation. Prentice-Hall International, Inc.

Budi Handayani, Septiwiyanti. 2016. Rancangan Teknis Sistem Penyaliran Tambang di Blok Gayam dan Kelapa Enam Desa Mekar Utama, Kec. Kendawangan, Kab. Ketapang, Provinsi Kalimantan Barat, PT. Harita Prima Abadi Mineral (Doctoral dissertation, UPN" Veteran" Yogyakarta).

Chakti, A.M., \& Rusli, HAR. 2021. Perencanaan Sistem Penyaliran Tambang, Studi Kasus: PIT. Timur Bukit Wrangler PT. ANTAM Tbk. Unit Bisnis Pertambangan Nikel Sulawesi Tenggara. Bina Tambang, 6(2), 72-83.

Cherry, R.F.J. 1979. Groundwater Prentice Hall Englewood Cliffs. New Jersey, 603.

FETTER, C. 1993. Contaminant Hydrogeology Macmillan Publishing Company, 458 pages. New York.

Gautama, RS. 2019. “Sistem PenyaliranTambang”. Bandung: ITB Press.

. 2012. "Pengelolaan Lingkungan pada Kegiatan Pertambangan". Slide Presentasi. Teknik Pertambangan ITB.

Gautama, RS dan Prahastini, SD. 2012. "Perancangan Aplikasi Untuk Sistem Penyaliran Tambang Terbuka”. Jurusan Teknik Pertambangan FTM: ITB.

Lesmana, D.M.M., Waterman, W., \& Maimina, M. (2019, September). Kajian Teknis Sistem Penyaliran Tambang Terbuka pada PIT Alpha PT. Timah Investasi Mineral, Kecamatan Kabaena Barat, Kabupaten Bombana, Sulawesi Tenggara. In Prosiding Seminar Nasional Sains dan Teknologi Terapan (Vol. 1, No. 1, pp. 501-506).

Lidayul, Dara. 2016. "Perencanaan Sumuran (Sump) Pada Sistem penyaliran Tambang Terbuka Di PIT IV Tambang Batubara PT. Bara Energi Lestari, Kabupaten Nagan Raya, Aceh". TugasAkhir. Aceh: Universitas Syiah Kuala.

Pipin Rio Sianturi, Maulana Yusuf, dan Hartini Iskandar. 2019. "Kajian Teknis Sistem Pengelolaan Air pada KolamPengendapan di Settlinng Pond North 3 untuk Memenuhi Standar Peraturan Gubernur Kalimantan Selatan No. 36 Tahun 2008." Jurnal PertambanganVol.3 No.1 (ISSN 2549-1008). Hlm. 1-9.

Raflesia, Chandrika. 2016. "Perencanaan Sistem Penyaliran di Blok B Rawa Seribu Tambang Batu Bara PT. Mandala Karya Prima Job Site PT. Mandiri Inti Perkasa Kalimantan Utara". Skripsi. Padang: Universitas Negeri Padang.

Rika. 2019. "Produktivitas Alat Di PT. Antam UBPB Tayan, Kalimantan barat". Skripsi. Padang: Universitas Negeri Padang 
Stella Putri Pratama, dan Tamrin Kasim. "Perencanaan Sistem PenyaliranTambang Batubara Bawah Tanah Seam C1 Blok Timur Site Sapan Dalam PT Nusa Alam Lestari Desa Salak, SapanDalam, Kota Sawahlunto, Sumatera Barat.” Jurnal Pertambangan (ISSN: 2302-3333). Hlm. 1-10.

Sugiono. 2012. Buku Metode Penelitian Kuantitatif, Kualitatif dan R \& D. Bandung: Alfabeta.

Syaifullah Aziz, dan Tamrin Kasim. "Evaluasi Sistem Penyaliran Tambang Tambang Batu Bara pada PIT Block B di PT. Minemex Indonesia Kabupaten Sarolangun, Jambi." Jurnal Bina Tambang, Vol 4, No 1 (ISSN: 2302-3333). Hlm. 1-12.

Te, C. V. 1989. Hidrolika Saluran Terbuka (Open Channel Hydrolics) Terjemahan. Erlangga, Jakarta, 2(5), 10.

Thamrin, Meinarni. 2016. "Desain Kolam Pengendapan (Settling Pond)". Makasar: Universitas Hasanuddin.

Widayat, W.S. 2012. Rancangan Sistem Penyaliran Tambang Bukit 01 Tambang Selatan di PT. Aneka Tambang (Persero) Tbk Unit Bisnis Pertambangan Nikel Pomalaa Sulawesi Tenggara (Doctoral dissertation, UPN" Veteran" Yogyakarta).

www.engineeringtoolbox.com. 2016. "Dirt and Mud Densities". Diakses tanggal: 3 Maret 2020.

Yastavia, R., \& Yulhendra, D. 2020. Evaluasi Teknis Penambangan Bauksit dari Front Penambangan Menuju Washing Plant Area untuk Menganalisis Faktor Ketidaktercapaian Target Produksi Berdasarkan Efisiensi Biaya Operasional Penambangan PT. ANTAM Tbk. UBPB Tayan, Kalimantan Barat. Bina Tambang, 5(1), 11-25. 